\title{
Molecular genetic analysis of the NF2 gene in young patients with unilateral vestibular schwannomas
}

\author{
A Mohyuddin, W J Neary, A Wallace, C L Wu, S Purcell, H Reid, R T Ramsden, A Read, \\ G Black, D G R Evans
}

J Med Genet 2002;39:315-322

See end of article for authors' affiliations

Correspondence to Mr A Mohyuddin, FRCS, University Department of Medical Genetics and Regional Genetic Services, St Mary's Hospital, Hathersage Road, Manchester M13 OJH, UK; atai_1999@yahoo.com

Revised version received 20 February 2002

Accepted for publication 26 February 2002

\begin{abstract}
Neurofibromatosis type 2 (NF2) must be suspected in patients presenting with a unilateral vestibular schwannoma at a young age who are therefore at theoretical risk of developing bilateral disease. We identified 45 patients aged 30 years or less at the onset of symptoms of a unilateral vestibular schwannoma. Molecular genetic analysis of the NF2 gene was completed on peripheral blood samples in all 45 and on 28 tumour samples. No pathogenic NF2 mutations were identified in any of the blood samples. NF2 point mutations were identified in 21/28 (75\%) tumour samples and loss of heterozygosity $(\mathrm{LOH})$ in $21 / 28(75 \%)$ tumour samples. Both mutational hits were identified in 18/28 (65\%) tumour samples. In one multilobular tumour, one (presumably first hit) mutation was confirmed which was common to different foci of the tumour, while the second mutational event differed between foci. The molecular findings in this patient were consistent with somatic mosaicism for NF2 and the clinical diagnosis was confirmed with the presence of two meningiomas on a follow up MRI scan. A further patient developed a contralateral vestibular schwannoma on a follow up MRI scan in whom neither of the truncating mutations in the vestibular schwannoma were present in blood.

It is important when counselling patients with unilateral vestibular schwannomas to identify (1) those at risk of bilateral disease, (2) those at risk of developing other tumours, and (3) other family members at risk of developing NF2. Comparing tumour and blood DNA cannot exclude mosaicism in the index case and cannot, therefore, be used to predict those at risk of developing further tumours. However, identification of both mutations or one mutation plus $\mathrm{LOH}$ in the tumour and exclusion of those mutations in the blood samples of the sibs or offspring of the affected case may be sufficient to render further screening unnecessary in these relatives.
\end{abstract}

$\mathrm{T}$ he majority (>95\%) of vestibular schwannomas are sporadic and unilateral and present in the fourth and fifth decades. ${ }^{12}$ In these cases they have no broader clinical implications for either patient or family. When bilateral, the tumours $^{23}$ represent a manifestation of neurofibromatosis type II (NF2), an autosomal dominant condition, which has a population incidence of 1 in 33000 to 1 in $40000 .{ }^{4}$ The hallmark of NF2 is the development in the second and third decades of bilateral vestibular schwannomas. NF2 is also characterised by a predisposition to the development of other tumours of the central and peripheral nervous system, including meningiomas, gliomas, and spinal schwannomas/ neurofibromas. ${ }^{5}$ Diagnostic criteria for NF2 were agreed by the National Institutes of Health Consensus Development Conference in 1987 (table 1A) and additional criteria described by Evans et al in 1992 (table 1B). There is evidence to suggest that patients aged 30 years or less at the onset of symptoms of a unilateral vestibular schwannoma are at high risk of being affected with a variant form of NF2. ${ }^{78}$ Approximately 10-18\% of NF2 cases present initially with a unilateral vestibular schwannoma rather than with bilateral tumours. However, this is usually accompanied or preceded by other features such as meningiomas, skin tumours, symptomatic spinal tumours, or a family history of NF2. ${ }^{6-11}$

Vestibular schwannomas arise from the inactivation of merlin, the protein product of the NF2 tumour suppressor gene, which regulates Schwann cell growth. Sporadic tumours differ from inherited tumours in that the first mutational hit is acquired and may be present in mosaic form. Subjects who are mosaic for a NF2 mutation are at risk of transmitting the mutation to their offspring if it is present in the gonads. ${ }^{12}$

The NF2 gene was isolated in $1993,{ }^{13}{ }^{14}$ after linkage studies had assigned the gene to chromosome 22. ${ }^{15}$ Germline mutations have been reported by several workers in large series of patients affected with NF2 ${ }^{16-19}$ However, only about $40 \%$ of de novo cases of NF2 have an identifiable mutation in lymphocyte DNA. ${ }^{12} 20$ As patients who present with a unilateral

Table 1 Diagnostic criteria for NF2

A diagnosis of NF2 is made in a patient who has (NIH criteria, 1987):

Bilateral vestibular schwannomas

OR family history of NF2

PLUS unilateral vestibular schwannoma

OR any two of: meningioma, glioma, neurofibroma, schwannoma, posterior subcapsular lenticular opacities

A diagnosis of NF2 can also be made in a patient who has (Evans et al $)^{k}$ :

Unilateral vestibular schwannoma

PLUS any two of: meningioma, glioma, neurofibroma, schwannoma, posterior subcapsular lenticular opacities

OR multiple meningiomas ( 2 or more)

PLUS unilateral vestibular schwannoma

OR any two of: glioma, neurofibroma, schwannoma, cataract 
Table 2 Redesigned primers for amplification of NF2 exons

\begin{tabular}{lll}
\hline Name & Forward primer $\left(5^{\prime} \rightarrow 3^{\prime}\right)$ & Reverse primer $\left(5^{\prime} \rightarrow 3^{\prime}\right)$ \\
\hline NF2 Ex 1 & tggccctgaggcctgtgcagcaac & gagaacctctcgagcttccac \\
NF2 Ex 2 & tgtccttccccattggtttg & cagtttcatcgagttctagcc \\
NF2 Ex 3 & gcttctttgagggtagcaca & ggtcaactctgaggecaactctgca \\
NF2 Ex 6 & - & cccataaaggaatgtaaaccaac \\
NF2 Ex 8 & gagcctcagctggcgcttac & - \\
\hline
\end{tabular}

vestibular schwannoma at a young age are at risk of developing bilateral disease, it would be valuable to identify those who require further screening for NF2 tumours. There are also implications for other family members who could require tumour surveillance and genetic counselling.

We have previously proposed a strategy, based on the analysis of tumour DNA, for distinguishing familial and sporadic cases of tumours caused by the inactivation of a tumour suppressor gene. ${ }^{21}$ We have now applied this strategy by completely analysing tumour material from 28 of 45 young patients with an apparently isolated unilateral vestibular schwannoma to establish whether the mutations present in the tumour are the result of a germline mutation or are likely to be the result of somatic events.

\section{METHODS \\ Patients}

Patients who presented with the onset of first symptoms of a unilateral vestibular schwannoma when aged 30 years or less were included in this study. All patients who had a family history of any neurogenic tumours were excluded from the study. All patients who were included in this study were examined clinically for any cutaneous features of NF2. Patients underwent ophthalmological examination to look for juvenile posterior subcapsular lenticular opacities and cortical opacities. A neuro-otological examination, which included pure tone audiometry, stapedial reflex measurement, and auditory brain stem response testing, was also performed. Magnetic resonance imaging with gadolinium-DTPA enhancement was used to assess all patients after 1990, so that a contralateral vestibular schwannoma or any other cranial tumour could be excluded.

A total of 689 patients who presented with a unilateral vestibular schwannoma were seen at the neuro-otology clinic between January 1978 and December 1998. In an earlier study we selected 93 of 407 of these patients on geographical criteria for a detailed study of patients and families with a unilateral vestibular schwannoma. ${ }^{7}$ Six patients were recruited from this retrospective series. The remainder of the series were recruited from patients meeting the inclusion criteria. Thirty patients who met these criteria from our hospital series were studied by looking at both their clinical features and analysing for NF2 mutations in both tumour and blood. The remaining 15 patients referred from other centres with an apparently isolated unilateral vestibular were analysed on blood alone.

\section{DNA extraction}

DNA was extracted from blood and tumour (fresh and paraffin fixed) specimens from 30 out of 45 cases. DNA was available only from blood in the remaining 15 samples. Genomic DNA was extracted from peripheral blood lymphocytes using standard procedures. DNA was prepared from fresh and paraffin embedded tumour specimens according to the methods described by Wu et al. ${ }^{21}$ One tumour (case 10) appeared to be multifocal at surgery and separate foci were biopsied and processed separately.

\section{Molecular genetic analysis}

Genomic and tumour DNA samples were amplified for all 17 exons of the NF2 gene. The primers for the majority of exons used were those described by Merel et al. ${ }^{18}$ However, the primer pairs for exons 1,2, and 3 along with the reverse exon 6 and forward exon 8 primer were redesigned to include the whole exon and splice donor/acceptor sites (table 2).

\section{SSCP heteroduplex analysis}

SSCP/heteroduplex analysis was carried out on $32 \mathrm{~cm}$ long $8 \%$ (49:1 acrylamide:bis acrylamide ratio) native polyacrylamide gels run at $360 \mathrm{~V}$ constant voltage for approximately 16 hours at $4^{\circ} \mathrm{C}$. SSCP and heteroduplexes were then visualised by silver staining. ${ }^{22}$ Samples that gave rise to SSCP/heteroduplex shifts, which were present at low levels on silver stained SSCP/HA (minority alleles), were reamplified and a larger quantity of the sample was loaded onto a second SSCP/HA gel. The gel was subjected to silver staining as previously except that the fourth solution was replaced with $50 \mathrm{mmol} / \mathrm{l}$ EDTA. The gel slices were briefly rinsed in $50 \mu \mathrm{l}$ sterile water and DNA was eluted by crushing and soaking overnight in $50 \mu \mathrm{l}$ of sterile water. The minority alleles isolated from the gel were then reamplified by PCR from the eluate.

\section{DNA products purification and sequencing}

The samples were purified before sequencing using Centricon 100 columns. A $40 \mu \mathrm{l}$ PCR reaction was added to $2 \mathrm{ml}$ of sterile water on the columns according to the manufacturer's instructions. The purified DNA products were then visualised on a $2.5 \%$ agarose gel to check for recovery. DNA sequencing reactions were carried out in both forward and reverse orientations for each sample using Big Dye Terminator v 20 ready reaction kits. Electrophoresis and fluorescent detection of the sequencing reactions was carried out on an Applied Biosystems 377A sequencer with $48 \mathrm{~cm}$ well to read plates.

\section{Loss of heterozyosity (LOH) studies}

$\mathrm{LOH}$ was detected using a combination of four microsatellite markers: D22S275, ${ }^{23}$ NF2CA3, ${ }^{24}$ D22S268, ${ }^{25}$ and D22S280. ${ }^{26}$ NF2CA3 is located within intron 1 of the NF2 gene whereas D22S275, D22S268, and D22S280 are all tightly linked to the NF2 gene. ${ }^{27}$ For markers D22S275, NF2CA3, and D22S268. $\mathrm{LOH}$ was determined using fluorescently labelled PCR products, the lymphocyte and tumour DNA pairs being amplified and subjected to simultaneous electrophoretic analysis to compare lymphocyte and tumour DNA using the Genescan v2.1.1 fragment analysis program. A diminution in relative allele signal strength between lymphocyte and tumour DNA of more than $30 \%$ was taken as indicative of LOH. For the marker D22S280, LOH was determined by comparison of lymphocyte and tumour DNA. PCR amplifications were electrophoresed on non-denaturing gels and visualised by silver staining.

\section{RESULTS}

The mean age of onset of symptoms in the 30 patients where blood/ tumour analysis was carried out was 23.1 years. This compared with 47.5 years for our hospital based series of 689 patients with unilateral VS. The average duration from age of onset of the first symptoms to age at which the patients were diagnosed as affected with a unilateral vestibular schwannoma was 3.7 years. There were 16 females and 14 males. The 


\begin{tabular}{|c|c|c|c|c|c|c|}
\hline Case & Sex & Age at first symptoms $(y)$ & Age at diagnosis $(y)$ & Other NF2 features & $\begin{array}{l}\text { Family } \\
\text { history }\end{array}$ & Conclusion after DNA studies \\
\hline 1 & $M$ & 18 & 26 & Nil & Nil & Sporadic \\
\hline 2 & $\mathrm{~F}$ & 19 & 23 & Nil & Nil & Sporadic \\
\hline 3 & $\mathrm{~F}$ & 24 & 27 & Nil & Nil & Sporadic \\
\hline 4 & $\mathrm{~F}$ & 19 & 22 & CAL patches & Nil & Sporadic \\
\hline 5 & M & 17 & 37 & Nil & Nil & Sporadic \\
\hline 6 & $\mathrm{~F}$ & 29 & 34 & Nil & Nil & Undetermined \\
\hline 7 & $\mathrm{~F}$ & 29 & 39 & Nil & Nil & Sporadic \\
\hline 8 & $M$ & 29 & 31 & Nil & Nil & Undetermined \\
\hline 9 & $M$ & 25 & 29 & One CAL: lump anterior thigh & Nil & Sporadic \\
\hline 10 & $\mathrm{~F}$ & 25 & 29 & *2 meningiomas & Nil & Mosaic \\
\hline 11 & $\mathrm{~F}$ & 18 & 20 & $\mathrm{Nil}$ & Nil & Sporadic \\
\hline 12 & $M$ & 25 & 26 & Nil & Nil & Sporadic \\
\hline 13 & $\mathrm{~F}$ & 17 & 24 & Nil & Nil & Undetermined \\
\hline 14 & $M$ & 24 & 27 & One CAL patch & Nil & $16 / 17$ exons analysed \\
\hline 15 & $\mathrm{~F}$ & 20 & 21 & $\mathrm{Nil}$ & Nil & Sporadic \\
\hline 16 & $M$ & 18 & 21 & Nil & Nil & Sporadic \\
\hline 17 & $M$ & 30 & 31 & $\mathrm{Nil}$ & Nil & Undetermined \\
\hline 18 & $M$ & 23 & 24 & One CAL patch & $\mathrm{Nil}$ & $5 / 17$ exons analysed \\
\hline 19 & $\mathrm{~F}$ & 18 & 21 & Nil & Nil & $\begin{array}{l}\text { Insufficient material for tumour } \\
\text { analysis }\end{array}$ \\
\hline 20 & M & 25 & 29 & One SC lump & Nil & Sporadic \\
\hline 21 & $M$ & 22 & 24 & $\mathrm{Nil}$ & Nil & Sporadic \\
\hline 22 & $\mathrm{~F}$ & 21 & 25 & Nil & Nil & Sporadic \\
\hline 23 & $\mathrm{~F}$ & 26 & 28 & $5 \mathrm{CAL}$ patches & Nil & Sporadic \\
\hline 24 & $\mathrm{~F}$ & 30 & 32 & Nil & Nil & Sporadic \\
\hline 25 & $\mathrm{~F}$ & 23 & 24 & Nil & $\mathrm{Nil}$ & Sporadic \\
\hline 26 & $\mathrm{~F}$ & 26 & 28 & $\begin{array}{l}3 \text { CaL patches and } \\
\text { contralateral VS* }\end{array}$ & Nil & Mosaic \\
\hline 27 & $\mathrm{~F}$ & 26 & 29 & Nil & Nil & Sporadic \\
\hline 28 & $M$ & 29 & 30 & Nil & Nil & Sporadic \\
\hline 29 & $M$ & 24 & 26 & Nil & Nil & Sporadic \\
\hline 30 & $M$ & 14 & 16 & Nil & Nil & Sporadic \\
\hline
\end{tabular}

$\mathrm{CAL}=$ café au lait. $\mathrm{SC}=$ subcutaneous

*Only after initial assesment of MRI; sporadic status is assumed, although mosaicism cannot be excluded.

clinical details are summarised in table 3 . None of the patients had a family history of vestibular schwannoma or other cranial tumours.

Café au lait patches were found on cutaneous examination in six separate cases, with one case (case 23) having five café au lait patches. Subcutaneous lumps were found in two cases (cases 9 and 20), but neither had been biopsied as these were not suspected clinically to be schwannoma. All the patients selected for the study were followed up with regular clinical, audiological and radiological examination. One patient (case 10) was subsequently also found to have two ipsilateral cranial meningiomas on follow up MRI scan. A further patient (case 26) developed a contralateral vestibular schwannoma three and a half years after undergoing surgery for a unilateral vestibular schwannoma. Twenty-two out of 689 patients in the hospital series had a unilateral vestibular schwannoma on initial cranial scan, but had other NF2 features or had a unilateral vestibular schwannoma and a family history; 13 of these fulfilled NF2 criteria and seven presented at less than 30 years of age. All were excluded from the present study population. All other 28 patients remain well with no cranial tumours on follow up MRI scan three to 20 years after initial diagnosis.

\section{Molecular genetic analysis} Analysis of lymphocyte DNA

Forty-five patients were tested for germline mutations from lymphocyte DNA and two of them were found to have sequence changes. The mutations identified in the blood samples of these two patients (cases 2 and 9) were considered to be non-pathogenic NF2 polymorphisms. An in frame deletion 332-4 was identified in blood from one patient (case 9), which was subsequently found in his unaffected mother (fig lA), and was thought not to be pathogenic. Two pathogenic mutational hits were identified in the tumour sample from the patient. A truncating mutation was identified which was not detectable in the lymphocyte DNA sample (fig 1B). The tumour also showed clear evidence of $\mathrm{LOH}$ with markers D22S275 and D22S268 (fig 1C). The allele lost in the tumour is that containing the in frame $3 \mathrm{bp}$ deletion since the signal from this is diminished. As a consequence, the truncating mutation is presumably on the other allele. The patient's mother has no clinical features of NF2, and MRI with gadolinium-DTPA enhancement showed no evidence of vestibular schwannomas or other cranial tumours. A synonymous codon substitution was also identified in one further patient (case 2).

\section{Analysis of tumour DNA}

Tumours of 28 patients were analysed for point mutations throughout the whole coding sequence of the NF2 gene. The results of the analysis are shown in table 4 .

Point mutations were identified in 21/28 tumour samples $(75 \%)$. Loss of heterozygosity ( $\mathrm{LOH}$ ) was present in $21 / 28$ tumour samples (75\%). Two mutational hits were identified in $18 / 28$ tumours $(65 \%)$ and a single mutational event established in $7 / 28(24 \%)$. In three out of $28(11 \%)$ tumours, no mutational event was found. In 21/28 tumour samples there were truncating mutations, with frameshift deletions occurring in 11 out of $21(52 \%)$ and nonsense mutations in eight out of $21(38 \%)$. Two tumours had splice site mutations $(9.5 \%)$. Two patients (cases 10 and 26 ) have subsequently developed second NF2 related tumours. Case 10, in whom a clinical diagnosis of NF2 has since been confirmed by the presence of cranial meningiomas, developed a unilateral multilobular vestibular schwannoma. A missense mutation Val219> Met was confirmed to be common to two different foci of the tumour. In the first focus, a second hit was not identified. In the second focus, two further pathogenic mutations were found as minority alleles (fig $2 \mathrm{~A}-\mathrm{C}$ ). This same 
A

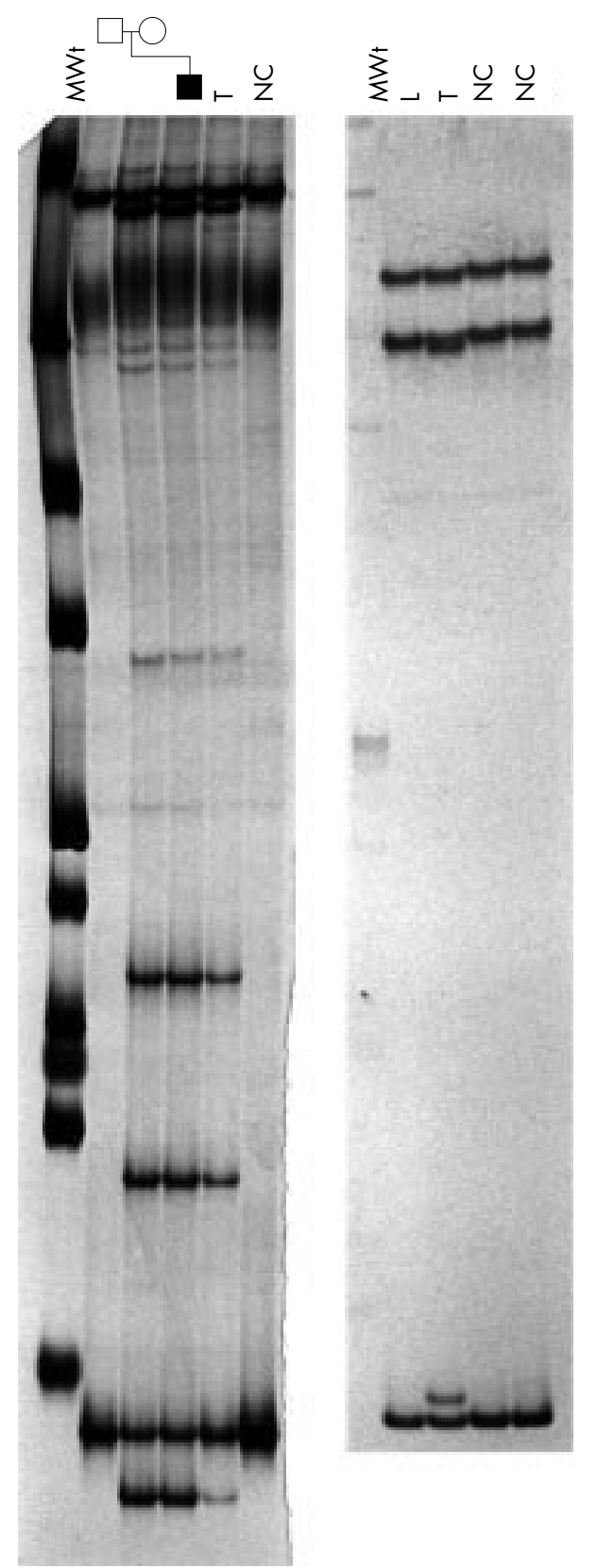

C

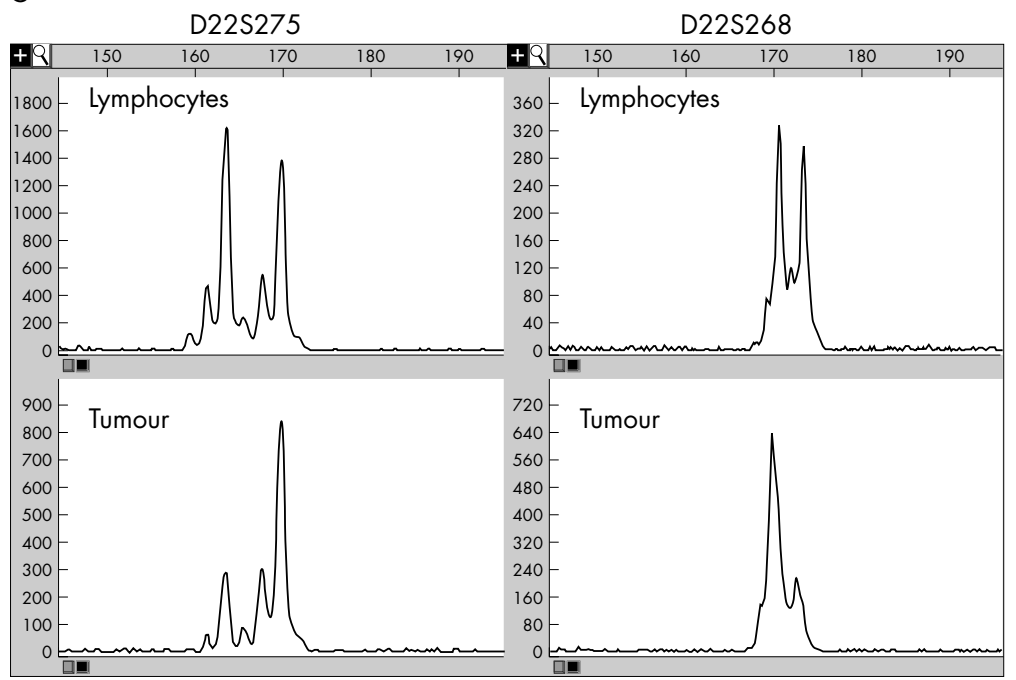

Figure 1 Molecular analysis of case 9. (A) SSCP/HA of exon 3. Lymphocyte DNA from both the patient and his parents are indicated by the pedigree. Both the patient and his unaffected mother clearly have a SSCP and heteroduplex shift; on sequencing this was found to be an in frame deletion of amino acid residue Glu 1 12. The tumour sample from the patient (T) also clearly has $\Delta \mathrm{glu} 112$, although the NF2 allele carrying $\Delta$ glu 112 shows diminution of signal indicating allele loss. (B) SSCP/HA analysis of exon 5. The tumour from case 9 has a SSCP and heteroduplex shift that is not present within his lymphocyte DNA sample (L); on sequencing this shift was found to be a nonsense mutation (Tyr 153>Stop, nt 459>G). The shift originating from Tyr >Stop is at approximately the same level as the normal signal. (C) LOH analysis. Comparison of lymphocyte and tumour DNA with the two closely linked microsatellite markers D22S275 and D22S268. An allele with both markers can be seen at markedly reduced intensity indicating allele loss in the tumour tissue. This sample was not informative for the intragenic marker NF2CA3. Mwt = molecular weight marker. NC = normal control.

biopsy specimen that showed three apparent mutations also showed evidence of LOH (fig 2D). However, the missense mutation was the predominant allele in this biopsy specimen. In the absence of a mutation in lymphocyte DNA from this patient, the findings were strongly suggestive of mosaicism. The daughter of this patient, who was therefore defined as being mosaic for NF2, has since been excluded as carrying the primary mutation, as well as the secondary mutations that were identified in her mother's tumour; she has therefore been excluded from tumour surveillance.
Case 26 has gone on to develop a contralateral vestibular schwannoma that was not detected on the original MRI scan. This patient carried two truncating mutations in the same exon in tumour DNA; the second splicing mutation (table 4) was initially overlooked as a mutation had already been identified in that exon. No abnormality was detected in her peripheral blood. She still has no other features of NF2 including a clear spinal MRI scan.

A further attempt to find a germline mutation was undertaken in the 10 out of 28 patients in whom two 
Table 4 SSCP/HA analysis and $\mathrm{LOH}$ studies on lymphocyte and tumour samples from 30 young patients with a unilateral vestibular schwannoma

\begin{tabular}{|c|c|c|c|c|c|c|c|}
\hline \multirow[b]{2}{*}{ Case } & \multirow[b]{2}{*}{ Tissue } & \multicolumn{2}{|l|}{$\mathrm{SSCP} / \mathrm{HA}$} & \multicolumn{4}{|c|}{ LOH analysis } \\
\hline & & Mutation & Class & D22S275 & NF2CA3 & D22S268 & D22S280 \\
\hline \multirow[t]{2}{*}{1} & L & -ve & - & & & & \\
\hline & T & $1080 \Delta G$ & $\mathrm{~F}$ & $\mathrm{LOH}$ & $\mathrm{LOH}$ & $\mathrm{LOH}$ & - \\
\hline \multirow[t]{2}{*}{2} & L & $465 C>T$ & SY & & & & \\
\hline & T & $\Delta 757-795(\Delta$ Lys253>Ser265) & IF & - & $\mathrm{LOH}$ & - & $\mathrm{LOH}$ \\
\hline \multirow[t]{2}{*}{3} & L & -ve & - & & & & \\
\hline & T & $1443 \mathrm{C}>\mathrm{G}$ (Tyr481>Stop) & $\mathrm{N}$ & $\mathrm{LOH}$ & u & $\mathrm{LOH}$ & - \\
\hline \multirow[t]{2}{*}{4} & L & -ve & - & & & & \\
\hline & T & 459C>A (Tyr153>Stop) & $\mathrm{N}$ & - & $\mathrm{LOH}$ & - & $\mathrm{N}$ \\
\hline \multirow[t]{2}{*}{5} & L & -ve & - & & & & \\
\hline & T & $448-1 g>t$ & SP & - & $\mathrm{LOH}$ & - & - \\
\hline \multirow[t]{2}{*}{6} & L & $-v e$ & - & & & & \\
\hline & T & $1228 \mathrm{C}>\mathrm{T}(\mathrm{G} \ln 433>$ Stop) & $\mathrm{N}$ & u & u & $\mathrm{N}$ & - \\
\hline \multirow[t]{2}{*}{7} & L & -ve & - & & & & \\
\hline & T & $970 C>T$ (Gln324>Stop) & $\mathrm{N}$ & $\mathrm{LOH}$ & U & $\mathrm{LOH}$ & - \\
\hline \multirow[t]{2}{*}{8} & L & -ve & - & & & & \\
\hline & T & -ve & - & $\mathrm{LOH}$ & u & $\mathrm{LOH}$ & - \\
\hline \multirow[t]{2}{*}{9} & L & 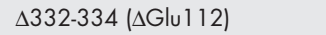 & IF & & & & \\
\hline & T & $459 C>G$ (Tyr153>Stop) & $\mathrm{N}$ & $\mathrm{LOH}$ & U & $\mathrm{LOH}$ & - \\
\hline 10 & L & $-\mathrm{ve}$ & - & & & & \\
\hline & $\mathrm{T} 1$ & $169 \mathrm{C}>\mathrm{T}$ (Arg57>Stop) & $\mathrm{N}$ & $\mathrm{LOH}$ & $U$ & U & - \\
\hline & & 655G>A (Val219>Met) & M & & & & \\
\hline & & $1600 \Delta C$ & $\mathrm{~F}$ & & & & \\
\hline & T2 & $655 \mathrm{G}>\mathrm{A}$ (Val2 19>Met) & M & $\mathrm{N}$ & U & u & - \\
\hline 11 & L & $-v e$ & - & & & & \\
\hline & T & $1514 \Delta \mathrm{TG}$ & $\mathrm{F}$ & - & $\mathrm{LOH}$ & - & - \\
\hline 12 & L & -ve & - & & & & \\
\hline & T & $479 \Delta \mathrm{G}$ & $\mathrm{F}$ & $\mathrm{LOH}$ & U & $\mathrm{LOH}$ & - \\
\hline 13 & L & $-v e$ & - & & & & \\
\hline & T & $\Delta 171-216$ & $\mathrm{~F}$ & NR & $\mathrm{N}$ & $\mathrm{N}$ & - \\
\hline 14 & L & $-v e$ & - & & & & \\
\hline & T & -ve for $16 / 17$ exons* & - & - & $\mathrm{LOH}$ & - & - \\
\hline 15 & L & -ve & - & & & & \\
\hline & $\mathrm{T}$ & $1513 \Delta \mathrm{CTGT}$ & $\mathrm{F}$ & $\mathrm{LOH}$ & U & u & - \\
\hline 16 & L & -ve & - & & & & \\
\hline & T & $169 C>T(\operatorname{Arg} 57>$ Stop $)$ & $\mathrm{N}$ & - & $\mathrm{LOH}$ & - & - \\
\hline 17 & L & -ve & - & & & & \\
\hline & T & $-v e$ & - & - & $\mathrm{LOH}$ & - & - \\
\hline 18 & L & $-v e$ & - & & & & \\
\hline & T & -ve for $5 / 17$ exons* & - & - & - & - & - \\
\hline 19 & L & -ve & - & & & & \\
\hline & T & insufficient material & - & - & - & - & - \\
\hline 20 & L & $-\mathrm{ve}$ & - & & & & \\
\hline & T & $1621 \Delta G$ & $\mathrm{~F}$ & - & $\mathrm{LOH}$ & - & - \\
\hline 21 & L & $-\mathrm{ve}$ & - & & & & \\
\hline & $\mathrm{T}$ & nt 1366 C>T (Glyn 456>stop) & - & - & $\mathrm{LOH}$ & - & - \\
\hline 22 & L & -ve & - & & & & \\
\hline & T & $447+2 t>c$ & SP & $\mathrm{N}$ & u & u & - \\
\hline 23 & L & $-v e$ & - & & & & \\
\hline & $\mathrm{T}$ & $653 \Delta G$ & $\mathrm{~F}$ & - & $\mathrm{LOH}$ & - & - \\
\hline 24 & L & -ve & - & & & & \\
\hline & T & 54 ins $A$ & $\mathrm{~F}$ & - & $\mathrm{LOH}$ & - & - \\
\hline 25 & L & $-v e$ & - & & & & \\
\hline & T & $-v e$ & - & - & $\mathrm{LOH}$ & - & - \\
\hline 26 & L & $-\mathrm{ve}$ & - & & & & \\
\hline & T & $737 \Delta C$ & $\mathrm{~F}$ & - & $\mathrm{N}$ & - & - \\
\hline 27 & L & $\begin{array}{l}\text { nt } 810 \mathrm{~g}>\mathrm{a} \\
-\mathrm{ve}\end{array}$ & $\begin{array}{l}\text { SP } \\
-\end{array}$ & & & & \\
\hline & $\mathrm{T}$ & $-v e$ & - & - & $\mathrm{N}$ & - & - \\
\hline 28 & L & $-\mathrm{ve}$ & - & & & & \\
\hline & T & $-v e$ & - & - & $\mathrm{N}$ & - & - \\
\hline 29 & L & $-v e$ & - & & & & \\
\hline & T & 265 ins $G$ & $\mathrm{~F}$ & - & $\mathrm{LOH}$ & - & - \\
\hline 30 & L & $-v e$ & - & & & & \\
\hline & T & $-\mathrm{ve}$ & - & $\mathrm{u}$ & u & $\mathrm{u}$ & - \\
\hline
\end{tabular}

mutational hits were not established in the tumour. Blood DNA was analysed by FISH analysis with probes LL96C10 and LL4D7 (courtesy of Jan Dumanski) and dosage PCR for exons $1,4,8$, and 15 . No further mutations were identified. No chil- dren of the unilateral vestibular schwannoma series has developed NF2. The daughter of the mosaic patient (case 10) has been excluded from carrying the mutations identified in her mother's tumour. 
A

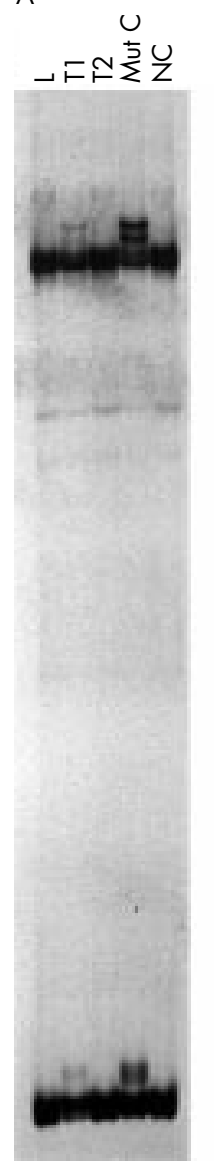

B

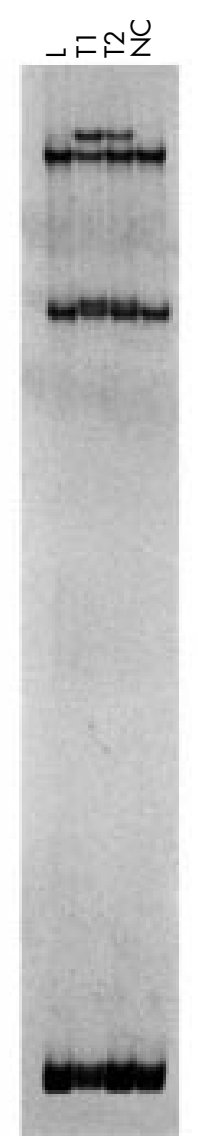

C

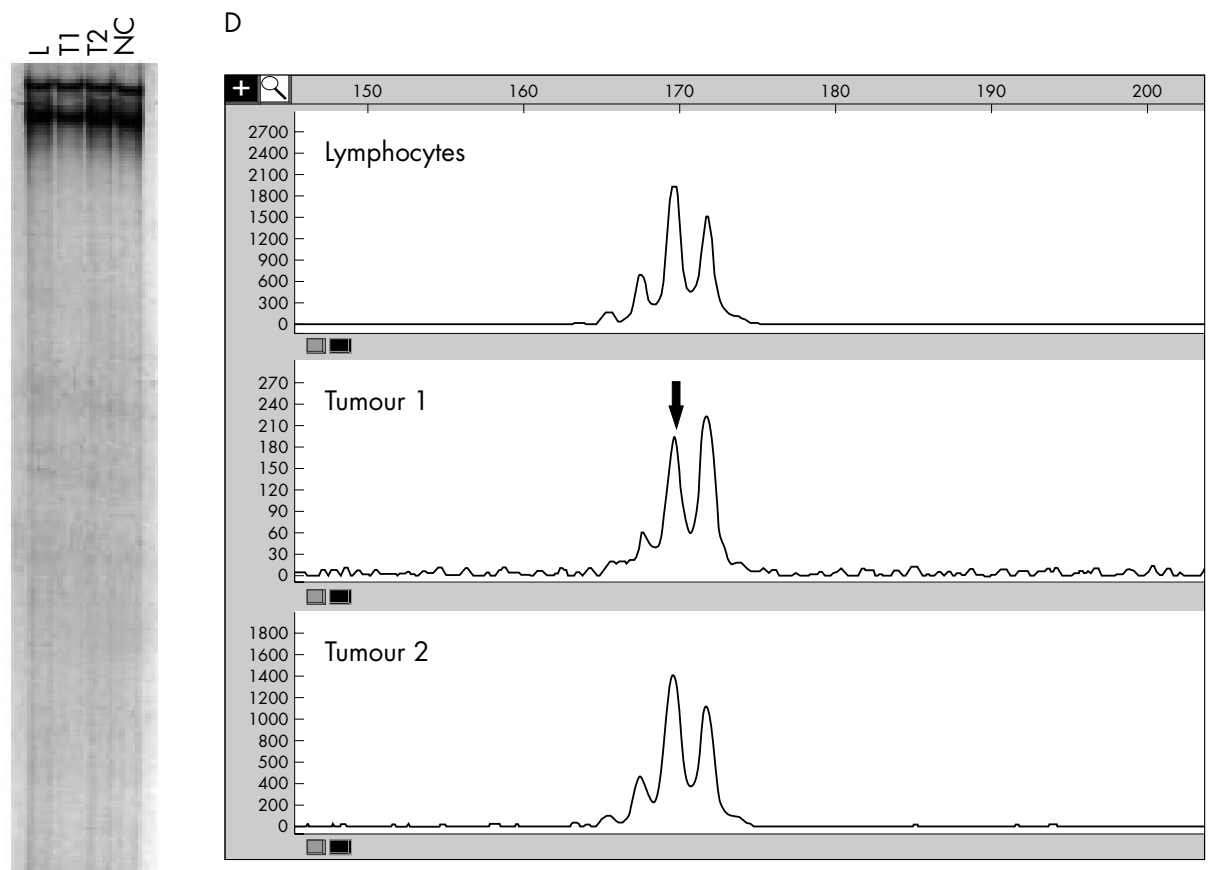

Figure 2 Molecular analysis of case 10. (A) SSCP/HA analysis of exon 2. The first sample from the tumour (T1) has a weak SSCP and heteroduplex shift that was sequenced as a nonsense mutation (Arg57>Stop, nt 169c>T). This shift is absent from the patient's lymphocyte DNA (L) and from the second tumour sample (T2). A mutation control has also been run from a patient who carries the same mutation in $50 \%$ of their lymphocytes (MutC). (B) SSCP/HA analysis of exon 7. Both tumour samples from case 10 (T1 and T2) have the same shift which was sequenced as a missense mutation (Val219>Met, nt 655G >A). The shift corresponding to Val2 19>Met is not present at detectable levels in the patient's lymphocyte DNA sample (L). The mutation appears to be present at a higher level in sample T1. (C) SSCP/HA analysis of exon 15. A very weak heteroduplex shift was observed in the first fumour sample (T1) which was sequenced as $1600 \Delta \mathrm{C}$. This shift was not observed at detectable levels in either the patient's lymphocyte DNA (L) or the second tumour sample (T2). (D) LOH analysis. Comparison of lymphocyte DNA and the two tumour DNA samples with the intragenic microsatellite marker NF2CA3. The first tumour sample shows significant but not complete loss of one allele (arrowed). There was no detectable allele loss in the second tumour sample. NC = normal control.

\section{DISCUSSION}

Vestibular schwannomas arise from the inactivation of the NF2 tumour suppressor gene, which regulates schwann cell growth. Vestibular schwannomas originate in the distal neurilemmal portion of the vestibular nerve at or close to the neurilemmal-neuroglial junction. ${ }^{28}$ They are benign neoplasms of the Schwann cell sheath.

This study has confirmed our recent work which shows that only a very small number of subjects with an isolated unilateral VS are likely to harbour a germline mutation in the NF2 gene or go on to develop bilateral disease. ${ }^{11}$ Out of the 45 young unilateral vestibular schwannoma patients thought to be at high risk of developing NF2, only two had identifiable sequence variations in blood samples (cases 2 and 9). Both were considered to be non-pathogenic polymorphisms. One of the two (case 9) had an identifiable sequence variation (loss of a glutamine at position 112 in the $\mathrm{N}$ terminal region), which, after further examination of the family and molecular analysis of his tumour, was confirmed to represent a rare polymorphism. This amino acid change was on the same allele that showed loss of heterozygosity and was present in the patient's mother, who had no evidence of cranial tumours on MRI aged 59 years.

One of these subjects, case 10 , is mosaic for a valine to methionine missense mutation at position 219, which is predicted to affect the normal conformation of the alpha helical domain. Given that this change was de novo (not present in germline DNA) and was confirmed in two separate foci of tumour, it is highly likely to be pathogenic. The results from one biopsy from the multifocal tumour in this case appears to show four separate hits, including LOH. It is likely that this biopsy has taken material from three separate foci of tumour; in this case the predominant allele contains the missense mutation present in all three foci.

The presence of multifocal tumours in NF2 has previously been described at the macroscopic level. ${ }^{1029}$ Unlike truly sporadic unilateral tumours, they often appear as a "bunch of grapes" around the vestibular nerve and may account for some of the poorer surgical and radiotherapy results in NF2. ${ }^{10}$ This is the first time to our knowledge that the multifocality of a vestibular schwannoma has been proven at the molecular level. A further lesson is seen in case 26 where two mutations were detected in the same exon to account for a SSCP shift, indicating that the entire sequence of the exon should be examined in a tumour specimen where two hits are possible.

It is possible that a predisposing mutation could be present in the 10 patients in whom two hits were not established. Zucman-Rossi et $a l^{30}$ have described a mutation screening strategy, which has raised the efficiency of mutation detection in NF2 patients to $84 \%$ in their series. Our combined strategy 
of SSCP, FISH, and dosage PCR is capable of detecting more than 90 per cent of mutations in the NF2 families (unpublished data in second generation). The standard mutation detection techniques such as single strand conformation polymorphism (SSCP) analysis or denaturing gradient gel electrophoresis, however, do not detect mutations in every classically affected patient. Also, the sensitivity of SSCP to detect mutations has been reported in various series to vary from $35-66 \% .^{17183132}$

In patients with unilateral tumours or without a family history, failure to detect a mutation in DNA from the patient's blood cannot be used as a means of analysing NF2; failure could be either because of low levels of mosaicism or a mutation undetected by our screening protocol. In $65 \%$ (18/28) of these apparently high risk subjects, it has been possible to exclude the presence of a pathogenic mutation in more than $10 \%$ of lymphocytes by identifying both hits in the tumour with none being detectable in blood. Mosaicism in NF2 is now a well described entity. ${ }^{12} 20$ Subjects who fulfil the modified NF2 diagnostic criteria (table $1 B$ ), such as case 10, are just as likely to have an identifiable NF2 mutation $^{12}$ as sporadic patients who fulfil the classical criteria of bilateral vestibular schwannomas. However, some patients like case 10 and a previously described case $\mathrm{e}^{21}$ have mosaicism, which appears to be predominantly on one side. While it is, of course, possible that case 10 may eventually develop bilateral disease, this may not by any means be certain. This pattern may therefore be more akin to previous reports of segmental disease in neurofibromatosis type $1 . .^{33}$

The data presented here, in conjunction with those from a retrospective analysis of over $300 \mathrm{NF} 2$ patients, ${ }^{11}$ suggest that while up to $18 \%$ of NF2 patients may present initially with a unilateral vestibular schwannoma, the great majority of these will have other features of NF2 at the time of diagnosis of their eighth nerve tumour or have a positive family history of NF2. Of the two subjects (cases 10 and 26) in this study who so far have gone on to develop NF2, one (case 10) had predictable features in her tumour, and while it is impossible to rule out mosaicism in any of the other patients, it is unlikely that the others will develop NF2. Indeed, only five patients of our previous series of over 300 NF2 patients presented with a sporadic unilateral vestibular schwannoma.

Therefore in patients with an apparently sporadic unilateral vestibular schwannoma, if there are no NF2 related diagnostic clinical features and no family history of NF2 related problems, it is highly unlikely that they will develop bilateral disease or pass on a pathogenic NF2 mutation to their offspring, even if they present at a very young age. In these young patients, as mosaicism cannot be excluded, a follow up MRI scan of the cranium is indicated at five and 10 years after diagnosis. ${ }^{34}$ Further mutational analysis of a blood-tumour pair will reduce any further theoretical risk. Once completed, offspring can be tested for NF2 mutations identified in the parental tumour in order to account for the small residual risk of germinal mosaicism.

\section{ACKNOWLEDGEMENTS}

The first two authors contributed jointly to this work. We wish to thank the NHS Executive North West and the Brenda Thornley Trust for their financial support for this research work and Mrs Celia Worsley for preparing paraffin sections of tumour samples. GB is a Wellcome Clinician Scientist Fellow.

\footnotetext{
Authors' affiliations

A Mohyuddin, A Wallace, C L Wu, S Purcell, A Read, G Black, D G R Evans, University Department of Medical Genetics and Regional Genetic Services, St Mary's Hospital, Hathersage Road, Manchester MI3 OJH, UK

W J Neary, Warrington Community Health Care (NHS) Trust, Child and Family Services Unit, Guardian House, Guardian Street, Warrington
}

WA5 ITP, UK

H Reid, Department of Pathology, Manchester Royal Infirmary, Oxford Road, Manchester M13 9WL, UK

\section{REFERENCES}

1 Pool JL, Pava AA, eds. The early diagnosis and treatment of acoustic nerve tumors. 1 st ed. Springfield, Illinois: C C Thomas, 1957:22

2 Pool JL, Pava AA, Greenfield EC. Acoustic nerve fumors - early diagnosis and treatment. 2nd ed. Springfield, Illinois: C C Thomas, 1970:23

3 Revilla AG. Neurinomas of the cerebellopontile recess: a clinical study of 160 cases including operative mortality and end results. Bull Johns Hopkins Hosp 1947;80:254-7

4 Evans DGR, Huson SM, Donnai D, Neary WJ, Blair V, Teare D, Newton $V$, Strachan T, Ramsden RT, Harris R. A genetic study of type 2 neurofibromatosis in the UK. I. Prevalence, mutation rate, fitness, and confirmation of maternal transmission effect on severity. J Med Genet 1992;29:841-6.

5 Martuza RL, Eldridge R. Neurofibromatosis 2 (bilateral acoustic neurofibromatosis). N Engl J Med 1988;318:684-8.

6 Evans DGR, Huson SM, Donnai D, Neary WJ, Blair V, Newton V, Harris R. A clinical study of type 2 neurofibromatosis. Q J Med 1992;84:603-18

7 Neary WJ, Newton VE, Laoide-Kemp SN, Ramsden RT, Griffith G, Evans DGR, Harris R, Strachan T. A clinical genetic and audiological study of patients and families with unilateral vestibular schwannomas. 1. Clinical features of neurofibromatosis in patients with unilateral vestibular schwannomas. J Laryngol Otol 1996; 110:634-40.

8 Parry DM, Eldridge R. Neurofibromatosis 2: groups at high risk. In: Proceedings of the First International Conference on Acoustic Neuroma. Copenhagen: Kugler Publications, 1992:811-14.

9 Parry DM, Eldridge R, Kaiser-Kupfer MI, Bouzas EA, Pikus A, Patronas N. Neurofibromatosis 2 (NF2): clinical characteristics of 63 affected individuals and clinical evidence for heterogeneity. Am J Med Genet 1994:52:450-61.

10 Evans DGR, Ramsden RT, Huson SM, Harris R, Lye R, King TT. Type 2 neurofibromatosis: the need for supraregional care? J Laryngol Otol 1993; 107:401-6.

11 Evans DGR, Lye R, Neary WJ, Black G, Strachan T, Wallace A, Ramsden RT. Probability of bilateral disease in people presenting with a unilateral vestibular schwannoma. J Neurol Neurosurg Psychiatry 1999:66:764-67

12 Evans DGR, Wallace A, Wu CL, Trueman L, Ramsden RT, Strachan T. Somatic mosaicism: a common cause of classic disease in tumor-prone syndromes? Lessons from type 2 neurofibromatosis. Am J Hum Genet 1998:63:727-36.

13 Trofatter JA, MacCollin MM, Rutter JL, Murrell JR, Duyao MP, Parry DM, Eldridge R, Kley N, Menon AG, Pulaski K, Haase VH, Ambrose CM, Munroe D, Bove C, Haines JL, Martuza RL, MacDonald ME, Seizinger BR, Short MP, Buckler AJ, Gusella JF. A novel moesin-ezrin-radixin like gene is a candidate for the neurofibromatosis 2 tumor suppressor. Cell 1993;72:791-800.

14 Rouleau GA, Merel P, Lutchman M, Sanson M, Zucman J, Marineau C, Hoang-Xuan K, Demczuk S, Desmaze C, Plougastel B, Pulst SM, Lenoir $G$, Biilsma $E$, Fashold R, Dumanski J, de Jong $P$, Parry D, Eldridge $R$ Aurias A, Delattre O, Thomas $G$. Alteration in a new gene encoding a putative membrane-organizing protein causes neurofibromatosis type 2 . Nature 1993;363:515-21

15 Rouleau GA, Wertelecki W, Haines JL, Hobbs WJ, Trofatter JA, Seizinger BR, Martuza RL, Superneau DW, Conneally PM, Gusella JF. Genetic linkage of bilateral acoustic neurofibromatosis to a DNA marker on chromosome 22. Nature 1987;329:246-8

16 MacCollin MM, Ramesh V, Jacoby LB, Louis DN, Rubio MP, Pulaski K, Trofatter JA, Short MP, Bove C, Eldridge R, Parry DM, Gusella JF. Mutational analysis of patients with neurofibromatosis 2. Am J Hum Genet 1994;55:314-20

17 Bourn D, Carter SA, Mason S, Evans DGR, Strachan T. Germline mutations in the neurofibromatosis type 2 tumour suppressor gene. Hum Mol Genet 1994;3:813-16.

18 Merel P, Hoang-Xuan K, Sanson M, Biilsma E, Rouleau G, Laurent-Puig $P$, Pulst S, Baser M, Lenoir G, Sterkers JM, Philippon J, Resche F, Mautner VF, Fischer G, Hulsebos T, Aurias A, Delattre O, Thomas G. Screening for germ-line mutations in the NF2 gene. Genes Chrom Cancer 1995; 12:117-27.

19 Parry DM, MacCollin MM, Kaiser-Kupfer MI, Pulaski K, Nicholson HS Bolesta M, Eldridge R, Gusella JF. Germ-line mutations in the neurofibromatosis 2 gene: correlations with disease severity and retinal abnormalities. Am J Hum Genet 1996;59:529-39.

20 Kluwe L, Mautner VF. Mosaicism in classical neurofibromatosis 2 patients. Hum Mol Genet 1998;7:2051-5.

21 Wu CL, Thakker N, Neary WJ, Black G, Lye R, Ramsden RT, Read AP Evans DGR. Differential diagnosis of type 2 neurofibromatosis: molecula discrimination of NF2 and sporadic vestibular schwannomas. J Med Genet 1998;35:973-7.

22 Wallace AJ. Combined single strand conformation polymorphism and heteroduplex analysis. In: Taylor GR, ed. Laboratory methods for the detection of mutations and polymorphisms in DNA. Boca Raton: CRC Press, 1997:79-94.

23 Weissenbach J, Gyapay G, Dib C, Vignal A, Morissette J, Millasseau P, Vaysseix $G$, Lathrop $M$. A second generation linkage map of the human genome. Nature 1992;359:794-801. 
24 Bourn D, Strachan T. Highly polymorphic dinucleotide repeat at the NF2 gene. Hum Genet 1995;95:712.

25 Marineau C, Baron C, Delattre O, Zucman J, Thomas G, Rouleau GA. Dinucleotide repeat polymorphism at the D22S268 locus. Hum Mol Genet 1993;2:336.

26 Gyapay G, Morissette J, Vignal A, Dib C, Fizames C, Millasseau P, Marc S, Bernardi G, Lathrop M, Weissenbach J. The 1993-94 Genethon human genetic linkage map. Nat Genet 1994;7:246-339.

27 Schuler GD, Boguski MS, Stewart EA, Stein LD, Gyapay G, Rice K White RE, Rodriguez Tome P, Aggarwal A, Bajorek E, Bentolila S, Birren BB, Butler A, Castle AB, Chiannilkulchai N, Chu A, Clee C, Cowles S, Day PJ, Dibling T, Drouot N, Dunham I, Duprat S, East C, Hudson TJ. A gene map of the human genome. Science 1996;274:540-6.

28 Skinner HA. The origin of acoustic nerve tumours. Br J Surg 1929;16:440-63

29 Martuza RL, Ojemann RG. Bilateral acoustic neuromas: clinical aspects, pathogenesis and treatment. Neurosurgery 1982;10:1-12.
30 Zucman-Rossi J, Legoix P, Der Sarkissian H, Cheret G, Sor F, Bernardi A, Cazes L, Giraud S, Ollagnon E, Lenoir G, Thomas G. NF2 gene in neurofibromatosis type 2 patients. Hum Mol Genet 1998;13:2095-101.

31 Jacoby LB, MacCollin MM, Louis DN, Mohney T, Rubio MP, Pulaski K, Trofatter JA, Kley N, Seizinger BR, Ramesh V, Gusella JF. Exon scanning for mutation of the NF2 gene in schwannomas. Hum Mol Genet 1994;3:413-19.

32 Kluwe L, Bayer S, Baser ME, Hazim W, Haase W, Funsterer C, Mautner VF. Identification of NF2 germline mutations and comparison with neurofibromatosis 2 phenotypes. Hum Genet 1996;98:534-8.

33 Riccardi VM, Eichner JE. Neurofibromatosis: phenotype, natural history and pathogenesis. Baltimore: Johns Hopkins University Press, 1986: 178-80.

34 Saeed SR, Woolford TJ, Ramsden RT, Lye RH. Magnetic resonance imaging: a cost-effective first line investigation in detection of vestibular schwannomas. Br J Neurosurg 1995;9:497-503

\section{$\mathrm{ECHO}$}

\section{When HFE gene mutation doesn't make sense}

ron accumulation and progress of liver disease in chronic hepatitis $\mathrm{C}$ infection are not due to HFE mutation, say Thorburn et al from a study of Scottish patients. Chronic infection results in iron build up in serum and the liver, with liver fibrosis. Iron overload in the liver and fibrosis are common to hereditary haemochromatosis, which is mostly caused by having homozygous recessive missense mutations in the HFE gene-either Cys282Tyr or His 63Asp. Some reports suggest that these mutations might underlie iron build up in chronic hepatitis $\mathrm{C}$ infection.

The present conclusion comes from a prospective study which screened 164 consecutive patients with chronic hepatitis C infection for HFE mutations, markers of iron accumulation in serum and liver, severity of liver disease, and viral genotype.

Sixty seven patients were heterozygous for HFE mutations: 26 Cys282Tyr, 33 His 63Asp, and eight

Please visit the Journal of Medical

Genetics Cys282Tyr/His 63Asp; seven were homozygous for either mutation and were excluded; and 90 had no mutation. No association between HFE genotype and any of the markers examined could be found when data for the 157 patients were analysed statistically. Thorburn et al were careful to test that 10

website non-Caucasian patients in their sample did not skew the results, nor did previous treatment with interferon, and they analysed the results for men and women separately in each of the four genotypic groups [www. imedgenet.com] for link to this to remove effects of age and menstruation.

Raised serum iron concentrations and HFE mutations may be evident in chronic hepatitis C infection, full article. but, seemingly, they are not linked.

\ Gut 2002;50:248-252. 